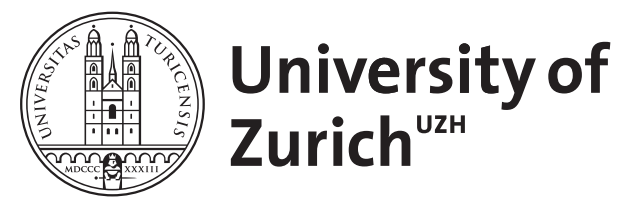

\title{
Technological change and the wealth of nations
}

Gancia, Gino ; Zilibotti, Fabrizio

\begin{abstract}
We discuss a unified theory of directed technological change and technology adoption that can shed light on the causes of persistent productivity differences across countries. In our model, new technologies are designed in advanced countries and diffuse endogenously to less developed countries. Our framework is rich enough to highlight three broad reasons for productivity differences: inappropriate technologies, policy-induced barriers to technology adoption, and within-country misallocations across sectors due to policy distortions. We also discuss the effects of two aspects of globalization, trade in goods and migration, on the wealth of nations through their impact on the direction of technical progress. By doing so, we illustrate some of the equalizing and unequalizing forces of globalization.
\end{abstract}

DOI: https://doi.org/10.1146/annurev.economics.050708.143333

Posted at the Zurich Open Repository and Archive, University of Zurich

ZORA URL: https://doi.org/10.5167/uzh-26928

Journal Article

Accepted Version

Originally published at:

Gancia, Gino; Zilibotti, Fabrizio (2009). Technological change and the wealth of nations. Annual Review of Economics, 1(1):93-120.

DOI: https://doi.org/10.1146/annurev.economics.050708.143333 


\title{
Technological Change and the Wealth of Nations*
}

\author{
Gino Gancia ${ }^{\dagger}$ and Fabrizio Zilibotti ${ }^{\ddagger}$
}

October 6, 2008

\begin{abstract}
We discuss a unified theory of directed technological change and technology adoption that can shed light on the causes of persistent productivity differences across countries. In our model, new technologies are designed in advanced countries and diffuse endogenously to less developed countries. Our framework is rich enough to highlight three broad reasons for productivity differences: inappropriate technologies, policy-induced barriers to technology adoption, and within-country misallocations across sectors due to policy distortions. We also discuss the effects of two aspects of globalization, trade in goods and migration, on the wealth of nations through their impact on the direction of technical progress. By doing so, we illustrate some of the equalizing and unequalizing forces of globalization.
\end{abstract}

JEL Classification: F43, O11, O31, O33, O38, O41, O43, O47.

Keywords: Barriers to Technology Adoption, Directed Technology Adoption, Endogenous Growth, Globalization, Human Capital, Inappropriate Technologies, Market Power, Political Economy, Skill-biased Technical Change, TFP differences.

\section{IntRoduCtion}

There is little disagreement that the unprecedented growth in material well-being experienced by Western countries over the past two centuries was made possible by crucial improvements in technology. Since the outset of the Industrial Revolution, pathbreaking innovations like the steam engine, the spinning machine, gas-lighting, electricity and the telegraph, opened the door to a trajectory of sustained technological change. While creating prosperity in some countries, the era of modern economic growth also led to the appearance of enormous disparities in the wealth of nations. Differences in income per capita between the richest and the poorest region in the world were a modest 3:1 in 1820 and became as large as 18:1 in 2001. Disparities across countries are far greater:

*We thank Daron Acemoglu for useful comments. Financial support by the European Research Council (ERC Advanced Grant IPCDP-229883), the Spanish Ministry of Education and Science (grant SEJ2005-01126 and Ramon y Cajal Program) and Generalitat de Catalunya (DURSI, SGR2005 0049) is gratefully acknowledged.

${ }^{\dagger}$ CREI and Universitat Pompeu Fabra. Email: ggancia@crei.cat.

${ }^{\ddagger}$ IEW - Zurich University. Email: zilibott@iew.uzh.ch. 
although they cannot easily be tracked back in time, in 2003, income per capita in the richest country (Luxembourg) was 143 times higher than in the poorest (Liberia).

Despite the obvious importance of technology in explaining modern growth and in shaping the world income distribution, quantifying the exact contribution of technical progress is not a simple task. The main difficulty is that technological progress is hard to observe and measure directly. To circumvent this problem, a useful starting point is the exercise of development accounting. It consists in choosing a functional form for the aggregate production function and use cross-country data on inputs and output to decompose differences in income per capita into differences in factor endowments (human and physical capital) and differences in total factor productivity (TFP). The goal of this decomposition is to shed light on the relative importance of productivity in explaining the differential performance of countries. The standard approach (see, e.g., Hall and Jones (1999) and Caselli (2005)) postulates that output per capita, y, can be represented by the following Cobb-Douglas function:

$$
y=A k^{\alpha} h^{1-\alpha},
$$

where $k$ is capital per worker, $h$ is average human capital per worker, $\alpha$ is a constant equal to the capital share, and $A$ is TFP. Having data on the observables $(y, k, h, \alpha)$, one can compute $A$ as a residual. Next, one can decompose the variance of $y$ into the contribution of factor accumulation and technology. The usual result in the literature is that differences in endowments, i.e. the factor $k^{\alpha} h^{1-\alpha}$, only account for less than $50 \%$ of the observed disparities in income per capita. ${ }^{1}$ In other words, TFP seems to be the main source of income differences.

In addition, convergence in measured TFP accounts for a large fraction of the changes in the wealth of nations. Take two success stories: China and the Republic of Korea. In 1970, the aggregate TFP of China was less than $12 \%$ of that of the United States. In 2003, it was over $38 \%$. In Korea, a country that started its process of fast convergence earlier, TFP was $36 \%$ of that of the United States in 1960, $46 \%$ in 1970 and $61 \%$ in 2003. In contrast, there has been no convergence in most Sub-Saharan African countries. For instance, Kenya's relative TFP was 25\% (twice as high as that of China!) in 1970 and only $21 \%$ in 2003. Similarly, Niger relative TFP was $31 \%$ in 1970 and $23 \%$ in $2003 .^{2}$

The development accounting exercise has intrinsic limitations. First, it identifies technology with an unexplained residual, and second it does not identify any ultimate cause for the observed variation in endowments and technology. Thus, while it provides evidence on the central role of productivity, it is mute about the nature of TFP differences as well as about the relationship between $h, k$ and $A$. Both economic theory and the positive empirical correlation between productivity and factor endowments (especially between human capital and TFP) suggest all factors $(k, h, A)$ to be endogenous and

\footnotetext{
${ }^{1}$ For example, Caselli (2005) finds that $\operatorname{var}\left[\log \left(k^{\alpha} h^{1-\alpha}\right)\right] / \operatorname{var}[\log (y)]=0.39$.

${ }^{2}$ The data of GDP per worker are from the Penn World Tables, version 6.2. Human capital per worker is defined using the average years of schooling in Barro and Lee (2000 and update http://www.cid.harvard.edu/ciddata/ciddata.html), a $10 \%$ annual rate of return to schooling. The estimate of human capital per capita in 2003 is based on the data for year 2000. The estimates of capital stock are from Bernanke and Gürkaynak (2001). We set $\alpha=1 / 3$ as customary.
} 
interlinked. For instance, both China and Korea experienced capital deepening and large improvements in the educational attainment as well as fast convergence. In contrast, neither Kenia nor Niger experienced capital deepening or technological change. Thus, it would be hazardous to infer deep causes of income differences from development accounting. Is the lack of human capita responsible for low levels of productivity? Are differences in complementary factors (human capital and TFP) what prevents capital per worker to be equalized across countries?

More recent studies have made some progress towards answering these questions. Gourinchas and Jeanne (2006) take the accounting exercise beyond its static perspective by explicitly allowing for endogenous physical and human capital accumulation. They propose an alternative decomposition of cross-country income disparities into three components: the distance of a country from its steady state, the steady state level a country is converging to, and residual productivity. To implement this decomposition, they use a calibrated neoclassical growth model where distortions to investments in both physical and human capital are chosen in order to match the observed pattern of saving rates and educational attainments. Their findings reinforce the basic message of the development accounting exercise, in the sense that a slow speed of convergence (i.e., the distance form the steady-state) contributes little to explaining cross-country income differences. For instance, even if non OECD countries could converge immediately to their steady state, they would fill a mere $15 \%$ of their income gap relative to the US economy. Distortions that lower the steady-state level of human and physical capital instead account for about $28 \%$ of output differences, still leaving the lion's share, almost $58 \%$, to unmeasured productivity.

Caselli and Feyrer (2007) provides further evidence on the source of cross-country differences in capital-labor ratios. They compute the marginal product of capital (MPK) for a large cross section of countries and find that, despite the huge variation in capitallabor ratios, MPK is remarkably similar. This result is interesting because it implies that capital is allocated efficiently across countries. To show this, they define the marginal product of reproducible capital, $M P K_{r}$, as:

$$
M P K_{r}=\alpha_{r} y / k_{r},
$$

where $k_{r}$ is reproducible capital and $\alpha_{r}$ is its income share. Although the overall capital share $\alpha$ is thought to be approximately constant across countries, less developed countries have a much larger share of agriculture and natural resource sectors that are intensive in non-reproducible capital. It follows that in poor countries $\alpha_{r}$ is particularly low. This correction (using $\alpha_{r}$ instead of $\alpha$ ) turns out to be very important to obtain the result that $M P K_{r}$ is almost equalized. Next, Caselli and Feyrer (2007) show that lower capital labor ratios in poor countries are largely attributable to low endowments of human capital and low productivity. Once again, these findings suggest that differences in capital endowments are a consequence rather than a cause of underdevelopment and that computing productivity as a residual in an accounting exercise may actually underestimate its role in explaining income differences.

In this paper, we construct a model that focuses on factor-biased (directed) technological change and use it as a workhorse to analyze a variety of interacting factors 
that explain persistent differences in the wealth of nations. We first argue, following Acemoglu and Zilibotti (2001), that since new technologies are developed by rich countries (the North) these technologies tend to be inappropriate for the factor endowments of poor countries. This mismatch between technologies and factor endowment in poor countries is a source of productivity differences. Moreover, we claim that the nature of recent technological development may have accentuated the importance of this channel. For instance, many less developed countries have a scarce endowment of skilled workers that are required to operate computer-intensive technologies. This reduces the positive impact of the IT revolution on their productivity widening the gap in the wealth of nations.

While Acemoglu and Zilibotti (2001) assume that technologies can be copied and adopted instantaneously, in the real world the diffusion of technologies across countries occurs slowly. This is partly due to physiological factor (e.g., new technologies embed some tacit knowledge or need to be adapted to local conditions). However, barriers to technology adoption may also have politico-economic roots, as argued among others by Parente and Prescott (1994 and 2000) and Krusell and Rios Rull (1997). Our model uncovers some of these politico-economic factors, focusing in particular on the aftermath of a skill-biased technological wave. We show that due to the skill bias of foreign technologies, the adoption of technologies developed in the North may harm incumbent firms and unskilled workers in the South, inducing them lobby for barriers that slowdown adoption. Competition policy is one of the most prominent policies affecting technology adoption. In the spirit of recent papers - see, e.g., Acemoglu, Aghion and Zilibotti (2006) and Zilibotti (2008) - an extension of our model shows that the optimal competition policy may change at different stages of the process of technological convergence. Both political barriers against technology adoptions and inappropriate competition policies can thus contribute to the persistent productivity differences.

In another application, we extend the analysis to the effects of asymmetric policy distortions, e.g., sector-specific industrial policies inducing different market power across sectors. Such policies open wedges that distort the direction of technological development and adoption. Our argument is related to a growing literature arguing that resource misallocations within countries may be a major culprit for the persistent low productivity in poor countries. Important contributions in this line of research include works by Parente, Rogerson and Wright (2000), Banerjee and Duflo (2005), Restuccia and Rogerson (2006), Hsieh and Klenow (2007) and Song, Storesletten and Zilibotti (2008).

Finally, we return to the benchmark model and analyze how globalization, undoubtedly one of the most important phenomenon of recent years, may affect the wealth of nations through its impact on the direction of technological progress. To this end, we open the model to international trade and labor mobility (migration). One important result of this section is to show that, as argued by Acemoglu and Zilibotti (2001) and Epifani and Gancia (2008a), globalization can lead to skill-biased technical change that benefits disproportionately skill-abundant countries. A second set of results obtains when countries are specialized in the production of differentiated goods. Within this framework, we discuss the point made by Acemoglu and Ventura (2002) that trade can 
promote technological convergence across countries through changes in relative prices (the terms of trade). Finally, we show that, depending on parameter values, the endogenous reaction of technology can turn migration into an either equalizing or unequalizing force. The latter finding allows us to make contact with a long tradition of models in which globalization can trigger a cumulative process of uneven development (e.g., Matsuyama (1995 and 2004) and Krugman and Venables, (1995)).

The paper is organized as follows. Section 2 presents the benchmark model of endogenous technical change. Section 3 introduces technology diffusion and uses the model as a workhorse to explore three sets of explanations for cross-country productivity differences: inappropriate technologies, barriers to technology adoption (and their origins), misallocation of resources across sectors. Section 4 introduces trade in goods and imperfect labor mobility. Section 5 concludes.

\section{The Benchmark Model}

In this section, we present the workhorse model of endogenous technical change. The benchmark model is a simplified version of Acemoglu, Gancia and Zilibotti (2008) - in turn related to Acemoglu (1998, 2002), Acemoglu and Zilibotti (2001) and Gancia and Zilibotti (2005). The key ingredients are different types of labor, skilled and unskilled workers, and factor-biased (directed) technical progress. To simplify the analysis, we abstract from physical capital accumulation. We emphasize an asymmetry in the ability of countries to "choose" technologies: new technologies are developed by rich countries (the North) and sold in their markets only, while new technologies need a costly investment to be adopted - possibly with delay - by less developed countries (the South). In this leader-follower approach, the South benefits from the innovation in the North but is also subject to a constraint on its ability to choose the appropriate factor bias of technology. We characterize first the equilibrium in the North, which can be interpreted as a large advanced country (or a collection of perfectly integrated advanced countries). In the next section, we model how technologies diffuse to a set of less developed countries (the South) and discuss sources of productivity differences.

\subsection{PREFERENCES}

The economy is populated by infinitely lived agents who derive utility from consumption $c_{t}$ and supply labor inelastically. Preferences of the representative agent are given by the utility function:

$$
U=\int_{0}^{\infty} e^{-\rho t} \log c_{t} d t
$$

where $\rho$ is the discount factor. The representative agent sets a consumption plan to maximize utility, subject to an intertemporal budget constraint and a No-Ponzi game condition. The consumption plan satisfies a standard Euler equation:

$$
\frac{\dot{c}_{t}}{c_{t}}=r_{t}-\rho
$$

where $r_{t}$ is the interest rate. We remove henceforth time indexes when this causes no confusion. 


\subsection{Technology and Market Structure}

Final output, used for both consumption and investment, is given by a CES aggregator

$$
Y=\left[Y_{L}^{\frac{\epsilon-1}{\epsilon}}+Y_{H}^{\frac{\epsilon-1}{\epsilon}}\right]^{\frac{\epsilon}{\epsilon-1}}
$$

where $Y_{L}$ and $Y_{H}$ are goods produced with unskilled labor, $L$, and skilled labor, $H$, respectively, and $\epsilon>1$ is the elasticity of substitution between them. Maximizing $Y$ under a resource constraint gives the relative demand function:

$$
\frac{P_{H}}{P_{L}}=\left[\frac{Y_{L}}{Y_{H}}\right]^{\frac{1}{\epsilon}}
$$

where $P_{L}$ and $P_{H}$ are the prices of $Y_{L}$ and $Y_{H}$, respectively. As usual, we take $Y$ to be the numeràire:

$$
P_{L}^{1-\epsilon}+P_{H}^{1-\epsilon}=1
$$

The production function at the sector level is:

$$
Y_{L}=E_{L}\left[\int_{0}^{A_{L}} y_{L}(i)^{\frac{\sigma-1}{\sigma}} d i\right]^{\frac{\sigma}{\sigma-1}} \text { and } Y_{H}=E_{H}\left[\int_{0}^{A_{H}} y_{H}(i)^{\frac{\sigma-1}{\sigma}} d i\right]^{\frac{\sigma}{\sigma-1}}
$$

where $A_{L}\left(A_{H}\right)$ is the measure of intermediate inputs, $y_{L}(i)\left(y_{H}(i)\right)$, produced with unskilled labor $L$ (skilled labor $H$ ). As in standard expanding-variety models à la Romer (1990), the range of available intermediates captures the state of technological sophistication that grows (endogenously) with innovation. The term $E_{L} \equiv\left(A_{L}\right)^{\frac{\sigma-2}{\sigma-1}}$ $\left(E_{H} \equiv\left(A_{H}\right)^{\frac{\sigma-2}{\sigma-1}}\right)$ is an externality that pins down the degree of increasing returns consistent with the existence of a balanced growth path. ${ }^{3}$ Producers of $Y_{L}$ and $Y_{H}$ are competitive and maximize profits taking the price of intermediates, $p_{L}(i)$ and $p_{H}(i)$, as parametric. This yields the demand equations:

$$
\frac{y_{L}(i)}{y_{L}(j)}=\left[\frac{p_{L}(j)}{p_{L}(i)}\right]^{\sigma} \quad \text { and } \quad \frac{y_{H}(i)}{y_{H}(j)}=\left[\frac{p_{H}(j)}{p_{H}(i)}\right]^{\sigma} .
$$

The intermediate good sector is monopolistic, with each producer owning the patent for a single variety. Note that intermediate firms are monopolist in their own product market, but behave competitively in the labor market since there they compete with a large number of firms. The production function for each intermediate input, $y_{L}(i)$ and $y_{H}(i)$, is linear in the type of labor employed,

$$
y_{L}(i)=l(i) \text { and } y_{H}(i)=Z h(i)
$$

\footnotetext{
${ }^{3}$ Note that the externality is not needed for the special case $\sigma=2$. In the typical formulation used in the literature without the term $E$ and with $\sigma \neq 2$ (e.g., Grossman and Helpman, 1991), balanced growth can be obtained by imposing an externality in the R\&D technology. Having the externality in the production function is no less general and simplifies the analysis substantially.
} 
and is subject to the resource constraints $\int_{0}^{A_{L}} l(i) d i \leq L$ and $\int_{0}^{A_{H}} h(i) d i \leq H$, where $L$ and $H$ are in fixed supply. The parameter $Z>1$ will ensure that the equilibrium skill premium is positive. As all monopolists face a demand curve with the constant price elasticity of $\sigma$, it is optimal for them to set a price equal to

$$
p_{L}(i)=p_{L}=\left(1-\frac{1}{\sigma}\right)^{-1} w_{L} \quad \text { and } \quad p_{H}(i)=p_{H}=\left(1-\frac{1}{\sigma}\right)^{-1} \frac{w_{H}}{Z},
$$

where $w_{L}$ and $w_{H}$ are the wage of unskilled and skilled workers, respectively. This pricing formula also implies that profits per firm are a fraction $1 / \sigma$ of revenues:

$$
\pi_{L}(i)=\frac{p_{L} l(i)}{\sigma} \quad \text { and } \quad \pi_{H}(i)=\frac{p_{H} Z h(i)}{\sigma}
$$

Using symmetry and labor market clearing yields $l(i)=L / A_{L}$ and $h(i)=H / A_{H}$, which in turn allows to express sectorial output as:

$$
Y_{L}=A_{L} L \quad \text { and } \quad Y_{H}=A_{H} Z H .
$$

Note that output in each sector is a linear function of labor and the measure of available intermediates, capturing the state of technology. Using these into (4) yields the relative price:

$$
\frac{P_{H}}{P_{L}}=\left[\frac{A_{L} L}{A_{H} Z H}\right]^{\frac{1}{\epsilon}} .
$$

Relative wages and profits can be found from (7), (8), noting that $p_{L} L=P_{L} Y_{L}$ and $p_{H} Z H=P_{H} Y_{H}$. This yields:

$$
\begin{aligned}
\frac{w_{H}}{w_{L}} & \equiv \omega=\frac{P_{H} Z A_{H}}{P_{L} A_{L}}=\left[\frac{Z A_{H}}{A_{L}}\right]^{1-\frac{1}{\epsilon}}\left[\frac{L}{H}\right]^{\frac{1}{\epsilon}} \\
\frac{\pi_{H}}{\pi_{L}} & =\frac{P_{H} Z H}{P_{L} L}=\left(\frac{A_{H}}{A_{L}}\right)^{-\frac{1}{\epsilon}}\left(\frac{Z H}{L}\right)^{1-\frac{1}{\epsilon}},
\end{aligned}
$$

where use has been made of (10). Equation (12) shows that the relative profitability, $\pi_{H} / \pi_{L}$, has two components: a "price effect", whereby rents are higher in sectors producing more expensive goods, and a "market size" effect, whereby rents are higher in bigger sectors.

\subsection{Endogenous Technological Change}

Innovation takes the form of the introduction of new varieties of intermediate inputs and is directed. In particular, we assume that the development of a new variety in sector $H$ $(L)$ requires a fixed cost of $\mu_{H}\left(\mu_{L}\right)$ units of the numeràire $Y$. For simplicity we assume that $\mu_{H}=\mu_{L}=\mu$. The direction of innovation is endogenous, i.e., each innovator can decide to design either a $L$ - or a $H$ - complement new variety. As patents are infinitely lived, the value of a firm - either $V_{L}$ or $V_{H}$ - is the present discounted value of its future 
profit stream. Free entry implies that neither $V_{L}$ nor $V_{H}$ can exceed the innovation cost, $\mu$. Since in a balanced growth path $P_{L}, P_{H}$ and the interest rate $r$ are constant, then:

$$
V_{L}=\frac{\pi_{L}}{r} \quad \text { and } \quad V_{H}=\frac{\pi_{H}}{r}
$$

In order for the relative price to remain constant, $A_{L}$ and $A_{H}$ must grow at the same rate, which in turns requires innovators to be indifferent between developing an $L$ - or $H$ complement input. Thus, $V_{L}=V_{H}=\mu$, which requires in turn that $\pi_{H} / \pi_{L}=1$. Then, equation (12) yields the skill bias of technology $\left(A_{H} / A_{L}\right)$ compatible with balanced growth: ${ }^{4}$

$$
\frac{A_{H}}{A_{L}}=\left(\frac{Z H}{L}\right)^{\epsilon-1} .
$$

From (11), the associated skill premium is:

$$
\omega=Z^{\epsilon-1}\left(\frac{H}{L}\right)^{\epsilon-2} .
$$

To find the growth rate of the economy, we note that along the balanced growth path the interest rate is pin down by any of the two free entry conditions:

$$
r=\frac{\pi_{H}}{\mu}=\frac{P_{H} Z H}{\mu \sigma}
$$

Solving for $P_{H}$ from (5) yields:

$$
P_{H}=\left[1+\left(\frac{P_{H}}{P_{L}}\right)^{\epsilon-1}\right]^{1 /(\epsilon-1)} .
$$

Using (16) together with (10), (13) and (15) we obtain an expression for $r$ that can be substituted into the Euler equation (2) to solve for the balanced growth rate of the economy, $g$ :

$$
g=r-\rho=\frac{\left[L^{\epsilon-1}+(Z H)^{\epsilon-1}\right]^{\frac{1}{\epsilon-1}}}{\mu \sigma}-\rho .
$$

\section{Directed Technology Adoption}

In this section, we extend the benchmark model to incorporate technology adoption in developing countries and use it as a workhorse to explore different explanations for the persistence of productivity differences across countries.

Consider a less developed country, called the South. We assume the South to be skill scarce relative to the North $\left(H^{S} / L^{S}<H^{N} / L^{N}\right)$ and to have a population size no larger than that of the North $\left(H^{N}+L^{N} \geq H^{S}+L^{S}\right)$. The South can adopt, at a cost specified below, the technologies developed in the North. Except for these differences,

\footnotetext{
${ }^{4}$ It can be shown that, from any initial state of the technology, the economy will converge monotonically to (13).
} 
the North and the South are identical. We also assume that there is no trade in goods and no international protection of intellectual property. The former assumption will be relaxed in Section 4.1. The latter implies that innovators in the North cannot sell their copyrights to firms located in the South, so that the only market they have access to is the domestic one (see Diwan and Rodrik (1991) for an empirical motivation of this assumption). In the absence of trade, the equilibrium conditions (2)-(17) in the North are unaffected by the presence of the South.

In the South, equilibrium conditions analogous to those in the North also apply, but the equilibrium technology takes a different form, as the South can adopt innovations developed in the North. In particular, the South takes the state of technology in the North, $A_{L}^{N}$ and $A_{H}^{N}$, as given. Technology adoption is modeled as a costly investment activity that is similar to innovation. Following Nelson and Phelps (1966), Barro and Sala-i-Martin (1997), and Acemoglu, Aghion and Zilibotti (2006) we assume that, due to technological spillovers, the cost of adopting a technology in a sector, $c_{L}$ and $c_{H}$, is a negative function of the technological gap in that sector: ${ }^{5}$

$$
c_{L}=\mu^{S}\left(\frac{A_{L}^{S}}{A_{L}^{N}}\right)^{\xi} \quad \text { and } \quad c_{H}=\mu^{S}\left(\frac{A_{H}^{S}}{A_{H}^{N}}\right)^{\xi}, \quad \xi \geq 0
$$

where $\mu^{S} \geq \mu$ (the South is less efficient than the North at innovating) and $A_{L}^{N}$ and $A_{H}^{N}$ represent the world technology frontiers in the two sectors. That is, the farther behind is a country relative to the North in a given sector, the cheaper it is to adopt technologies in that sector. With this formulation, the total cost of adopting the entire set of $z$-complement technologies (with $z \in\{H, L\}$ ) is:

$$
\mu^{S} \int_{0}^{A_{z}^{N}}\left(\frac{A_{z}^{S}}{A_{z}^{N}}\right)^{\xi} d A_{z}^{S}=\frac{\mu^{S} A_{z}^{N}}{1+\xi}
$$

This expression shows that $\xi$ can be interpreted as an inverse measure of barriers to technology adoption in the South.

The fact that the cost of adoption is positive (albeit arbitrarily small if $\xi \rightarrow \infty$ ) implies that once a firm adapt a new intermediate input to the South, it is not profitable for any others to do so. Otherwise, Bertrand competition between sellers of the same intermediate would lead to negative profits. Hence, all intermediate inputs adopted in the South are sold by local monopolists.

In a balanced growth equilibrium, free entry implies

$$
\frac{\pi_{H}}{\pi_{L}}=\frac{c_{H}}{c_{L}}
$$

where $c_{H}$ and $c_{L}$ are given by (18), and depend on the distance to the technology frontier in the respective sector. Then, using equations (12), (18) and (19), we can solve for the skill bias of the technology in the South:

$$
\frac{A_{H}^{S}}{A_{L}^{S}}=\left(\frac{Z H^{S}}{L^{S}}\right)^{\frac{\epsilon-1}{1+\epsilon \xi}}\left(\frac{A_{H}^{N}}{A_{L}^{N}}\right)^{\frac{\epsilon \xi}{1+\epsilon \xi}}=\left[\left(\frac{Z H^{S}}{L^{S}}\right)\left(\frac{Z H^{N}}{L^{N}}\right)^{\epsilon \xi}\right]^{\frac{\epsilon-1}{1+\epsilon \xi}}
$$

\footnotetext{
${ }^{5}$ See Coe, Helpman and Hoffmaister (2008) for empirical evidence on technological spillovers.
} 
Technology adoption in the South depends on the skill endowment in the North and in the South. On the one hand, a high skill-endowment in the South translates into a strong incentive to adopt skill-complement innovations. ${ }^{6}$ On the other, a high skill-endowment in the North means that skill-complement innovations are relatively abundant and therefore relatively cheap to adopt. Note also that the skill-bias of the Southern technology, $A_{H}^{S} / A_{L}^{S}$, is increasing in $\xi$, capturing the speed of technology transfer. In particular:

1. If $\xi=0$ (prohibitive barriers) the South develops technologies independently from the North: $A_{H}^{S} / A_{L}^{S}=\left(Z H^{S} / L^{S}\right)^{\epsilon-1}$;

2. If $\xi \rightarrow \infty$ adoption is free (no barriers) so that the South is using the technology of the North: $A_{H}^{S} / A_{L}^{S}=A_{H}^{N} / A_{L}^{N}$.

It is easy to show that, in a balanced growth path, the South grows at the same rate $g$ as the North and the two countries have the same interest rate, even in the absence of trade or factor mobility.

We use this model of technology adoption to explore the three explanations for North-South productivity differences discussed in the introduction:

1. Technology inappropriateness;

2. Barriers to technology adoption and inappropriate competition policies;

3. Inefficiencies arising from distortions which create a wedge between social and private productivity of investments in innovation/technology adoption.

To illustrate (1) and (2), it will prove useful to focus on the transitional dynamics associated with a shock inducing skill-biased technical progress. This exercise is interesting also because skill-biasedness has been argued to be an important feature of technological progress in the last quarter of the XXth century (an example being the IT revolution, see, e.g., Katz and Murphy (1992) and Berman, Bound and Machin (1998)). Following Acemoglu (1998), we model the shock as an exogenous increase in the skill supply of the region of the world where technical change originates (the North). Alternatively, we could consider the unexpected emergence of a new general purpose technology such as information technology (see, e.g., Helpman and Trajtenberg (1998) and Aghion and Howitt (1998)), that reduces the cost of innovation of the skilled sector. Both shocks would induces skill-biased technical change in the North: since $\pi_{H} / \mu_{H}>\pi_{L} / \mu_{L}, A_{H}$ grows and $A_{L}$ remains constant during the transition. We study the implications of this shock and the ensuing transition on cross-country productivity differences, on the one hand, and on within-country income distribution, on the other hand. As we shall see, the latter may be responsible of lobbying activities to block technology adoption.

\footnotetext{
${ }^{6}$ Caselli and Wilson (2004) provide evidence that countries import technologies that complement their abundant factors.
} 


\subsection{Inappropriate TeChNologies}

Even if countries have access to the same technologies $\left(\xi \rightarrow \infty\right.$, implying that $A_{H}^{S} / A_{L}^{S}=$ $\left.A_{H}^{N} / A_{L}^{N}=A_{H} / A_{L}\right)$, technologies developed in rich countries may not be appropriate for the needs of poor countries. The reason is that there might be a technology-skill mismatch: when the South is using technologies that are designed for the North economy, it may lack the skill endowment required to operate them optimally. For example, very poor countries with low literacy rates may lack the skills that are necessary to benefit fully from the IT revolution.

To address this point formally, we start by showing that if technical change originates entirely in the North its direction is efficient from the viewpoint of the North itself. An efficient allocation maximizes the PDV utility of the representative consumer, given by

$$
U_{0}=\int_{0}^{\infty} e^{-\rho t} \log \left[Y_{t}-\mu\left(\dot{A}_{L t}+\dot{A}_{H t}\right)\right] d t,
$$

where aggregate output can be written - substituting (9) into (3)- as:

$$
Y_{t}=\left[\left(A_{L t} L\right)^{\frac{\epsilon-1}{\epsilon}}+\left(Z A_{H t} H\right)^{\frac{\epsilon-1}{\epsilon}}\right]^{\frac{\epsilon}{\epsilon-1}} .
$$

Standard analysis shows that since the marginal cost of innovation is the same across sectors, an efficient direction of technical change equalizes the marginal product of technology across sectors - i.e., the technology maximizes output. Differentiating (21) yields: ${ }^{7}$

$$
\frac{\partial Y}{A_{L}}=Y^{\frac{1}{\epsilon}} L^{\frac{\epsilon-1}{\epsilon}}\left(A_{L}\right)^{\frac{-1}{\epsilon}} \quad \text { and } \quad \frac{\partial Y}{A_{H}}=Y^{\frac{1}{\epsilon}}(Z H)^{\frac{\epsilon-1}{\epsilon}}\left(A_{H}\right)^{\frac{-1}{\epsilon}} .
$$

Thus:

$$
\frac{\partial Y}{A_{L}}=\frac{\partial Y}{A_{H}} \Leftrightarrow \frac{A_{H}}{A_{L}}=\left(\frac{Z H}{L}\right)^{\epsilon-1}
$$

which coincides with the equilibrium skill-bias in the North of equation (13). Hence, the direction of technology is optimal for the Northern skill-composition.

An immediate implication is that if less developed countries use the technology originating from the North, but have a different relative skill endowment, $H^{N} / L^{N} \neq H^{S} / L^{S}$, then $A_{H} / A_{L} \neq\left(H^{S} / L^{S}\right)^{\epsilon-1}$. Thus, the marginal product of technology will not be equalized in the South and the productivity of the South will be below the level that would be attained if it could chose its technological bias. To see this, define the productivity per effective unit of labor as $y \equiv Y /(Z H+L)$ and consider how the productivity gap varies with the skill bias in the technology:

$$
\frac{y^{N}}{y^{S}}=\frac{Z H^{S}+L^{S}}{Z H^{N}+L^{N}}\left[\frac{1+\left(\frac{A_{H}}{A_{L}} \frac{Z H^{N}}{L^{N}}\right)^{\frac{\epsilon-1}{\epsilon}}}{1+\left(\frac{A_{H}}{A_{L}} \frac{Z H^{S}}{L^{S}}\right)^{\frac{\epsilon-1}{\epsilon}}}\right]^{\frac{\epsilon}{\epsilon-1}} .
$$

\footnotetext{
${ }^{7}$ Note that this condition does not concern the amount of innovation - which is suboptimally too low - but only its direction.
} 
The right-hand side expression is an increasing function of $A_{H} / A_{L}$, because the North is assumed to be skill-abundant. This shows that the skill bias of technology magnifies the productivity difference. Note also that the skill-technology mismatch disappears as $\epsilon \rightarrow 1$. This reflects the well-know fact that, when the aggregate production function is Cobb-Douglas $(\epsilon=1)$, the factor-bias of technology is irrelevant.

The analysis of this section suggests an alternative approach to the empirical questions discussed in the introduction. The development accounting literature attributes productivity differences due to differences in technologies that are captured by different levels of the TFP parameter in the aggregate production function (1). To assess the importance of inappropriate technologies, one can instead assume that all countries use the same technologies, but that the skill bias of the aggregate technology reflects the direction of technological progress in the North. For instance, Acemoglu and Zilibotti (2001) consider a model that has a reduced-form representation similar to the one discussed in this section, but allow for differences in capital-labor ratios. In particular, their aggregate production is

$$
Y=K^{\alpha}\left[\left(A_{L} L\right)^{\frac{\epsilon-1}{\epsilon}}+\left(Z A_{H} H\right)^{\frac{\epsilon-1}{\epsilon}}\right]^{\frac{(1-\alpha) \epsilon}{\epsilon-1}}
$$

where, in their model, $\epsilon=2$. They set $\alpha=1 / 3$, and replace $K, L$ and $H$ by the countryspecific level in a particular year. Finally, they calibrate $Z, A_{H}$ and $A_{L}$ so as to match the skill premium in the US, and assume them to have the same value in all countries - implying that all countries use the same technologies but the skill bias of technologies is determined by the factor endowment of the US. They find that their model can explain up to $50 \%$ of the observed cross-country productivity differences. Reducing the elasticity of substitution between capital and labor improves further the fit of the model (see Caselli 2005). These results suggest that technological inappropriateness may be quantitatively important in explaining productivity differences.

It is also interesting to see how economies respond to a shock inducing skill-biased technical change (e.g., an increase in $H^{N}$ ). Figure 1 summarizes the main features of the transition for a case in which $\epsilon>2$. The economy is initially in a balanced growth equilibrium, where $A_{H}$ and $A_{L}$ grow at the same rate. Since the South imports costlessly the technologies invented in the North, $A_{H}^{N}=A_{H}^{S}=A_{H}$ and $A_{L}^{N}=A_{L}^{S}=A_{L}$. At time $t_{0}$, there is an unexpected increase in $H^{N}$. As the shock occurs, $A_{L}$ stops growing whereas the growth rate of $A_{H}$ increases discontinuously. During the transition, the growth rate of $A_{H}$ slows down, as the resulting fall in the relative price $P_{H} / P_{L}$ reduces profitability in the skilled sector and increases profitability in the unskilled sector. Eventually, innovation is restored in both sector, and the new balanced growth features higher growth. The intermediate panel shows the dynamics of the skill premium in the North and in the South. At $t_{0}$, the skill premium falls in the North. However, thereafter the skill premium starts to rise in both countries. Since $\epsilon>2$, inequality increases in the long run both in the North and in the South. Yet, the growth in inequality is more pronounced in the South, where the relative skill endowment has not changed. Finally, the lower panel shows that skill-biased technical change increases permanently the productivity gap between the North and the South. 


\section{FIGURE 1 HERE}

\subsection{Barriers to Technology Adoption}

In the previous section, we have assumed that the South can adopt technologies invented in the North at essentially no cost. Although this was useful to isolate the effect of technology inappropriateness, the assumption that technologies diffuse immediately is clearly not realistic. First, new technologies embed some tacit knowledge that cannot be acquired instantaneously. Second, there are specific local features that may require costly adaptation of foreign technologies. Third, there are often institutional and policy barriers that limit technology diffusion. To analyze these issues, we consider in this section the general case in which technology adoption is costly $(\xi<\infty)$. The theory will be used to highlight distributional implications of technology adoption in the South that may lie behind incentives to erect barriers against adoption. To this aim, we assume that the government in the South can affect the parameter $\xi$ through regulations on the use of foreign technologies. Setting as low barriers as possible (high $\xi$ ) fosters technology adoption and overall productivity growth in the South. However, importing foreign technologies may harm some groups of workers - in particular, as we will see, low-skill workers - and incumbent monopolists in the South.

\subsubsection{Workers}

Consider, first, the effects of $\xi$ on wages. The skill premium in the South can be obtained from substituting the expression of $A_{H}^{S} / A_{L}^{S}$ in (20) into the formula for the skill premium, (11):

$$
\frac{w_{H}^{S}}{w_{L}^{S}}=Z^{\frac{(\xi+1)(\epsilon-1)}{\epsilon \xi+1}}\left(\frac{H^{S}}{L^{S}}\right)^{\frac{\epsilon-\xi-2}{1+\epsilon \xi}}\left(\frac{A_{H}^{N}}{A_{L}^{N}}\right)^{\frac{(\epsilon-1) \xi}{1+\epsilon \xi}}=Z^{\epsilon-1}\left(\frac{H^{S}}{L^{S}}\right)^{\frac{\epsilon-\xi-2}{1+\epsilon \xi}}\left(\frac{Z H^{N}}{L^{N}}\right)^{\frac{(\epsilon-1)^{2} \xi}{1+\epsilon \xi}} .
$$

The second equality follows from (13), recalling that $A_{H}^{N} / A_{L}^{N}$ is determined by the factor endowment in the North. As $H^{S} / L^{S}<H^{N} / L^{N}$, the skill premium increases with $\xi$ showing that more technology transfer increases wage inequality. This effect can cause the surge of political pressure to raise barriers against technology adoption because, for instance, inequality may trigger social unrest or can make the middle class $(H)$ powerful enough to threat the incumbent government. Note that the unequalizing effect is decreasing in $H^{S} / L^{S}$. Thus, countries with higher educational attainments and less inequality may be subject to less political pressure against technology adoption, and this can contribute further to attain a higher productivity. Therefore, the mechanism analyzed in this section reinforces the results of Acemoglu and Zilibotti (2001) that in Southern countries skill-abundance reduces the TFP gap by reducing the mismatch between skills and technology.

Consider, next, the effect of a transition triggered by an increase in $H^{N}$. The repercussion in the South is a fall in $c_{H} / c_{L}$, whose effects on the technology bias are qualitatively similar to those observed in the North and visualized in Figure 1: the adoption 
of unskilled technologies is temporarily suspended and, during the transition, the South imports only skilled technologies. Since $A_{L}^{S}$ does not grow, wage inequality increases sharply, and more so the larger the elasticity of substitution between skilled and unskilled labor. Eventually, wage inequality settles down at a higher steady-state level.

In contrast, consider a policy response to the shock that blocks the introduction of foreign technology, i.e., it sets $\xi=0$. The transitional dynamics are in this case opposite. Before the shock, the following balanced-growth condition holds for the South

$$
1=\frac{\pi_{H} / c_{H}}{\pi_{L} / c_{L}}=\left(\frac{A_{H}^{S}}{A_{L}^{S}}\right)^{-\frac{1}{\epsilon}}\left(\frac{Z H^{S}}{L^{S}}\right)^{1-\frac{1}{\epsilon}}\left(\frac{A_{H}^{N}}{A_{H}^{S}} \frac{A_{L}^{S}}{A_{L}^{N}}\right)^{\xi} .
$$

As the third term in parenthesis on the right-hand side is larger than unity, a policy reducing $\xi$ would imply $\pi_{H} / c_{H}<\pi_{L} / c_{L}$. Thus, switching to "autarky" in innovation would induce unskill-biased technical change: $A_{L}^{S}$ would grow whereas $A_{H}^{S}$ would remain constant until a new balanced-growth equilibrium is reached. In the new balanced growth, the skill premium is low. Thus, the barriers would benefit unskilled workers, at least in the short run. Note that in the extreme case in which $\xi=0$ and $\mu^{S}>\mu$, prohibitive barriers would cause divergence between the North and the South. Therefore, in the long run all factors would loose. Yet, to the extent to which future consumption is discounted, low-skill workers may still support barriers.

Although our discussion has focused on a particular episode (an exogenous increase in $H^{N}$ ), the thrust of the argument applies more generally. For instance, if the South had prohibitive barriers in place to start with, opening the sluice gate of technology transfer would halt temporarily the growth of $A_{L}^{S}$ and accelerate that of $A_{L}^{H}$. Along the transition, the South would only import skilled technology and witness an increase in wage inequality. This may explain why - contrary to the prediction of standard trade models - developing countries that become more open often experience increasing inequality. To the extent to which economic reforms increase not only the trade of goods but also the transfer of technology, their effect can be to increase inequality.

\subsubsection{Incumbent monopolist firms}

So far, we have considered the effect of technology adoption on wages, and the possibility that low-skill workers may lose from the adoption of foreign technologies. In reality, the political strength of low-skill industrial workers - while varying from country to country - is often limited in developing nations. A more politically empowered group that may resist to the introduction of new technologies is local incumbent monopolists. We now turn the attention to these firms.

Before starting the analysis, we note that standard endogenous growth models with expanding variety and no directed technical change - such as Romer (1990) - predict no effects of innovation on incumbent firms. In such models the entry of new firms does not affect the value of incumbents, due to the knife-edge properties of the Dixit-Stiglitz production function. Although our model does assume Dixit-Stiglitz technologies, the price effect associated with the direction of technical change has an impact on the value of incumbent firms leading to interesting politico-economic predictions. The effects of 
innovation on the value of incumbent firms tend to be asymmetric. When a shock triggers a transition through a change in relative prices, the value of firms in one sector falls. However, the value of incumbent firms in the sector potentially benefiting from the price change remains constant: rents are dissipated due to the entry of new firms. There is no counterpart to this entry process in the sector suffering an adverse price change, since there firms cannot exit and recover sunk costs. The change in prices must then lead to a temporary fall in the profits of these firms.

As in the previous section, we consider the effects of an unanticipated increase of $H^{N}$. In the North, if the number of firms remained constant, the increase in the skill endowment would increase the profitability of incumbent firms in the $H$ sector. This is known in the literature as a "market size effect". However, the entry of new firms offsets this effect and keeps the profit flow of incumbent firms in the $H$ sector constant. The value of monopolists remains equal to $V_{H}^{N}=\mu$. In contrast, the profit of incumbents in the $L$ sector falls, causing $V_{L}^{N}<\mu$. During the transition, the entry of firms in the skilled sector increases $P_{L}$, raising the value of firms in the $L$ sector until this eventually returns to $\mu$.

In the South, the value of all incumbent firms falls permanently creating a motive for existing firms to lobby for barriers against technology adoption. To show this, consider the profit flows in the two sectors. These are given by, respectively ${ }^{8}$

$$
\begin{gathered}
\pi_{L}^{S}=\frac{P_{L}^{S} L^{S}}{\sigma}=\frac{L^{S}}{\sigma}\left[1+\left(\frac{P_{L}^{S}}{P_{H}^{S}}\right)^{\epsilon-1}\right]^{\frac{1}{\epsilon-1}}=\frac{L^{S}}{\sigma}\left[1+\left(\frac{Z A_{H}^{S} H^{S}}{A_{L}^{S} L^{S}}\right)^{\frac{\epsilon-1}{\epsilon}}\right]^{\frac{1}{\epsilon-1}} \\
\pi_{H}^{S}=\frac{P_{H}^{S} Z H^{S}}{\sigma}=\frac{Z H^{S}}{\sigma}\left[1+\left(\frac{P_{H}^{S}}{P_{L}^{S}}\right)^{\epsilon-1}\right]^{\frac{1}{\epsilon-1}}=\frac{Z H^{S}}{\sigma}\left[1+\left(\frac{A_{H}^{S}}{A_{L}^{S}} \frac{Z H^{S}}{L^{S}}\right)^{-\frac{\epsilon-1}{\epsilon}}\right]^{\frac{1}{\epsilon-1}} .
\end{gathered}
$$

Note that the profit flow of firms in the low-skill (high-skill) sector is increasing (decreasing) in the skill bias of the technology $\left(A_{H}^{S} / A_{L}^{S}\right)$. In turn, the skill bias of the technology is increasing in both $H^{N} / L^{N}$ and $H^{S} / L^{S}$ (see equation (20)). Thus, the profit flow of firms in the low-skill sector is higher in the new balanced-growth equilibrium, since $H^{N} / L^{N}$ is larger than in the initial equilibrium. The profit flow of firms in the high-skill sector is instead lower in the new balanced-growth equilibrium. Recall, however, that the steady-state value of firms equals $\pi_{L}^{S} / r$ and $\pi_{H}^{S} / r$, respectively in the two sectors. The interest rate increases unambiguously, due to the market-size effect (see equation (17)). ${ }^{9}$ Thus, $V_{H}$ necessarily falls, while the sign of the change of $V_{L}$ is in principle ambiguous, since both $\pi_{L}^{S}$ and $r$ increase. However, the apparent ambiguity can be resolved

\footnotetext{
${ }^{8}$ These expressions are obtained using (8), (16) and (10).

${ }^{9}$ Note that $r$ is the same in the North and in the South in a balanced growth equilibrium in spite of no trade. The interest rate is instead generally different during transitions.
} 
to conclude that $V_{L}$ is also lower in the new steady state. To see why, note that ${ }^{10}$

$$
V_{L}^{S}=\mu \frac{L^{S}}{L^{N}}\left[\frac{1+\left(\frac{H^{S} / L^{S}}{H^{N} / L^{N}}\right)^{\frac{(\epsilon-1)(1+\xi)}{1+\epsilon \xi}}\left(\frac{Z H^{N}}{L^{N}}\right)^{\epsilon-1}}{1+\left(\frac{Z H^{N}}{L^{N}}\right)^{\epsilon-1}}\right]^{\frac{1}{\epsilon-1}} .
$$

The analysis of (25) shows that $V_{L}^{S}$ is decreasing in $H^{N} / L^{N}$.

To undertand this result, recall that in a balanced-growth equilibrium $V_{L}^{S}=c_{L}=$ $\mu^{S}\left(A_{L}^{S} / A_{L}^{N}\right)^{\xi}$ and $V_{H}^{S}=c_{H}=\mu^{S}\left(A_{H}^{S} / A_{H}^{N}\right)^{\xi}$. Thus, the fall in the value of Southern firms reflects the fact that the distance of the South from the technology frontier increases in all sectors. This is intuitive, as skilled-biased technical change increases the mismatch between the technologies invented in the North and the factor endowment of the South. However, the current section enlightens the fact that the effect of the technology mismatch on the productivity gap can be magnified by politico-economic forces creating a push for raising barriers to technology adoption. ${ }^{11}$

\subsection{Market Power, Growth and Development}

Innovation and technology transfer may also be slowed down by inappropriate policies that regulate the degree of competition between firms. The extent to which incumbent firms should be granted market power on their own product line is a classical theme in the endogenous growth literature. To address it formally, let us return to equation (7). A monopolist in the low-skill sector charges a price $p_{L}=(1-1 / \sigma)^{-1} w_{L}$. Now, assume that there exists a competitive fringe of firms that can copy the technology and produce the same intermediate good. But this fringe faces higher costs of production, and needs $(1-1 / \tilde{\sigma})^{-1}$ workers to produce one unit of the intermediate, where $(1-1 / \sigma)^{-1} \geq$ $(1-1 / \tilde{\sigma})^{-1}>1$. The parameter $\tilde{\sigma}$ captures both technological factors and government regulation affecting entry. In this generalization, the competitive fringe will not be active in equilibrium, but will force the monopolist to charge a limit price equal to the marginal cost of the fringe:

$$
p_{L}=\left(1-\frac{1}{\tilde{\sigma}}\right)^{-1} w_{L} .
$$

Thus, a lower $\tilde{\sigma}$ corresponds to a less competitive market, and setting $\tilde{\sigma}=\sigma$ corresponds to the unconstrained monopoly (maximum market power).

\footnotetext{
${ }^{10}$ The steady-state value of a firm is given by $V_{L}^{S}=\pi_{L}^{S} / r$. Using (23) to eliminate $\pi_{L}^{S}$ and (17) to eliminate $r$, and simplifying terms, yields:

$$
V_{L}^{S}=\frac{\pi_{L}^{S}}{r}=\mu \frac{L^{S}}{L^{N}}\left[\frac{1+\left(\frac{A_{H}^{S}}{A_{L}^{S}} \frac{Z H^{S}}{L^{S}}\right)^{\frac{\epsilon-1}{\epsilon}}}{1+\left(\frac{Z H^{N}}{L^{N}}\right)^{\epsilon-1}}\right]^{\frac{1}{\epsilon-1}}=\mu \frac{L^{S}}{L^{N}}\left[\frac{1+\left(\frac{H^{S} / L^{S}}{H^{N} / L^{N}}\right)^{\frac{(\epsilon-1)(1+\xi)}{1+\epsilon \xi}}\left(\frac{Z H^{N}}{L^{N}}\right)^{\epsilon-1}}{1+\left(\frac{Z H^{N}}{L^{N}}\right)^{\epsilon-1}}\right]^{\frac{1}{\epsilon-1}} .
$$

Finally, using (20) to eliminate $A_{H}^{S} / A_{L}^{S}$ yields (25).

${ }^{11} \mathrm{~A}$ shock decreasing $H^{N} / L^{N}$ would have an opposite long-run effect: the value of all incumbent firms in the South would be higher in the new steady state characterized by a lower mismatch and a smaller technology gap.
} 
Monopoly power is traditionally associated with an inefficient resource allocation, as monopolists set prices different from marginal costs and underproduce. Thus, static efficiency would be achieved by setting $\tilde{\sigma} \rightarrow \infty$. However, since the early 1990s, the endogenous growth literature has emphasized that the appropriation of monopoly rents is key to provide firms with the incentive to make innovative investments. Consequently, the growth literature has advocated a strong protection of intellectual property rights, although this view has been recently challenged (see Boldrin and Levine (2008)). The empirical evidence is ambiguous. For instance, Aghion et al. (2005) find a nonmonotonic relationship between market power and innovation. They rationalize their findings in a model where innovation is maximized when pre-innovation rents are small and post-innovation rents are large. Increasing competition has a stronger effect on preinnovation rents when competition is initially low - so a pro-competitive reform fosters innovation. In contrast, increasing competition in an already highly competitive environment - e.g., where incumbent firms are operating at similar technological levels affects more significantly post-innovation rents and reduces innovation.

As in standard endogenous growth model, our benchmark model predicts that the growth rate is maximized by granting monopolists the maximum power, i.e., setting $\tilde{\sigma}=\sigma$. Furthermore, there is no static inefficiency in our model due to the inelastic supply of labor and to the fact that labor cannot be used in other sectors. Thus, the growth-maximizing policy is also the optimal policy. In this section, we extend the model to show that under reasonable assumptions an excess of monopoly power may harm growth. Moreover, we relate this analysis to the process of development and we highlight how inappropriate competition policies may slow down technological convergence.

While most of the existing literature on competition policy and growth analyzes the process of innovation in the industrialized world, recent research has shifted its focus to the relationship between competition policy and technological convergence in the development process. Acemoglu, Aghion and Zilibotti (2006) argue that in countries behind the technological frontier there is a trade-off between the innovation and imitation activities carried out within firms. They argue that investments and the adoption of well established technologies through imitation are fostered by long-term relationships between firms, between firms and banks or between firms and their managers. In contrast, turnover and flexible contractual arrangements favor the selection of entrepreneurial skills, ultimately enhancing firms' innovative capabilities. Industrial policy, and in particular competition policy, determine what contracts are chosen in equilibrium. In particular, barriers to competition strengthen the position of insider firms and their managers. While harming the selection of the most productive firms, this policies can promote investments in poor economies where credit market imperfections are the most binding constraint. For this reason, barriers to competition may have been useful to promote growth and technological convergence in countries such as France, Italy, Korea and Japan that adopted interventionist industrial policies after World War II (see Zilibotti (2008) for more discussion), as long as they were sufficiently far from the technology frontier. However, the theory emphasizes that as economies approach the technology frontier, more market-oriented strategies implying lower barriers to competition are nec- 
essary to promote further technological convergence. This is because at this later stage technological convergence requires more human capital and selection to foster both genuine innovation and the adaptation of more sophisticated technologies. Such change of strategy can clash with the interests of insider firms that throve due to the high barriers to competition.

The theory described above breaks with the stark prediction that high monopoly power is best for growth. Moreover, it argues that as growth and technology adoption become more human-capital intensive the optimal policy becomes more pro-competitive. However, neither their theory nor the model of directed technical change presented in the previous section deals with human capital accumulation. In this section, we augment the model of directed technical change with educational investments. The extension identifies a mechanism by which excessive monopoly power has a negative effect on innovation and growth. In particular, when firms appropriate too large a share of the surplus, all other factors lose and in particular the return to human capital investment falls. Thus, the optimal policy depends on the extent to which countries rely on human capital accumulation for their growth and development process.

Since our argument applies to both innovation and technological convergence, we restrict attention to the one-country version of the model. We assume that $H$ can be accumulated. To obtain a balanced growth path where $A_{L}, A_{H}$ and $H$ grow at the same rate, we modify the technology in the $H$-intensive sector by assuming that

$$
Y_{H}=E_{H}\left[\int_{0}^{A_{H}} y_{H}(i)^{\frac{\sigma-1}{\sigma}} d i\right]^{\frac{\sigma}{\sigma-1}},
$$

where $E_{H} \equiv\left(A_{H}\right)^{\frac{\beta \sigma-\beta-1}{\sigma-1}} H^{-\beta} \cdot{ }^{12}$ For simplicity, we set $Z=1$. Given symmetry and full employment, we obtain that $Y_{H}=H^{1-\beta} A_{H}^{\beta}$.

Total profits in the $H$ sector are equal to a fraction $1 / \tilde{\sigma}$ of revenue. Thus, profits per firm are $\pi_{H}=P_{H}\left(H / A_{H}\right)^{1-\beta} / \tilde{\sigma}$ while the wage per unit of human capital is $w_{H}=P_{H}\left(1-\frac{1}{\tilde{\sigma}}\right)\left(\frac{A_{H}}{H}\right)^{\beta}$. Along the balanced growth path, the return from investing in innovation must be equal to the return from investing in human capital:

$$
\frac{\pi_{H}}{\mu}=\frac{P_{H}}{\tilde{\sigma} \mu}\left(\frac{H}{A_{H}}\right)^{1-\beta}=r=\frac{P_{H}}{c_{e}}\left(1-\frac{1}{\tilde{\sigma}}\right)\left(\frac{A_{H}}{H}\right)^{\beta}=\frac{w_{H}}{c_{e}},
$$

where $c_{e}$ is the cost of education (acquiring one unit of $H$ ). This arbitrage condition pins down the balanced growth ratio:

$$
h \equiv \frac{H}{A_{H}}=\frac{\tilde{\sigma}-1}{c_{e}} .
$$

\footnotetext{
${ }^{12}$ This assumption on $E_{H}$ may appear restrictive. We view it as a reduced-form representation of more realistic models that allow us to keep the analysis within the framework of the previous sections. For instance, a production function of the form:

$$
Y_{H}=\left(\frac{H}{A_{H}}\right)^{1-\beta} \int_{0}^{A_{H}} x_{i}^{\alpha} d i
$$

where intermediates $x_{i}$ are produced using the numeraire good, would produce very similar results. See, e.g., Dalgaard and Thustrup (2001) for a similar specification of technology.
} 
Finally, as in the benchmark model, relative prices along the balanced growth path are determined by the indifference condition between innovating in the two sectors:

$$
\frac{\pi_{H}}{\pi_{L}}=\frac{P_{H}}{P_{L}} \frac{h^{1-\beta}}{L}=1 \rightarrow \frac{P_{H}}{P_{L}}=\frac{L}{h^{1-\beta}}
$$

Using this, together with (16), we can solve for the profit levels:

$$
\pi_{H}=\frac{h^{1-\beta}}{\tilde{\sigma}}\left[1+\left(\frac{L}{h^{1-\beta}}\right)^{\epsilon-1}\right]^{1 /(\epsilon-1)} \quad \text { and } \quad \pi_{L}=\frac{L}{\tilde{\sigma}}\left[1+\left(\frac{h^{1-\beta}}{L}\right)^{\epsilon-1}\right]^{1 /(\epsilon-1)}
$$

Note that, for a given $h$, profits are a negative function of $\tilde{\sigma}$. Given that profits are a share $1 / \tilde{\sigma}$ of revenues, a low $\tilde{\sigma}$ tends to increase monopoly rents. However, a high profit rate (low $\tilde{\sigma}$ ), compresses wages and thus the return to human capital. This has the effect of reducing the equilibrium level of $h$ and hence of profits, because human capital is a complementary factor in production. This second effect implies that, when human capital can be accumulated, maximizing monopoly power is no longer the growth-maximizing policy. The growth-maximizing degree of competition depends on how important human capital is in production.

To see this, substitute (27) into $\pi_{L}$, then use $r=\pi_{L} / \mu$ and (2) to solve for the balanced growth rate:

$$
g=\frac{1}{\tilde{\sigma} \mu}\left[L^{\epsilon-1}+\left(\frac{\tilde{\sigma}-1}{c_{e}}\right)^{(1-\beta)(\epsilon-1)}\right]^{\frac{1}{\epsilon-1}}-\rho
$$

What $\tilde{\sigma}$ maximizes $g$ ? To answer this question, consider the following cases:

1. If $\beta \rightarrow 1$ or $c_{e} \rightarrow \infty$ or $L$ is very high, meaning that human capital is relatively unimportant or very scarce, then $g$ is decreasing in competition, $\tilde{\sigma}$, as in the benchmark model. Thus, in developing countries where human capital accumulation is not an important engine of growth, some anti-competitive arrangements may be growth-enhancing.

2. If instead $L \rightarrow 0$, then it is easy to show that $g$ is maximized for $\tilde{\sigma}=1 / \beta$. That is, the more relevant human capital is in production (low $\beta$ ), the lower the growth-maximizing level of monopoly power.

More generally, the more countries' growth relies on human capital accumulation, the more they need competitive markets. For instance, in a poor economy in transition where human capital investments are not profitable yet and where growth relies entirely on the adoption of foreign technologies, protecting monopoly rents speeds up the convergence path. Once investment in human capital starts, however, too high monopoly rents can become a barrier to growth. 


\subsection{Distortions and Technology Misallocation}

The analysis of sections 3.1 and 3.2 has shown that, conditional on the cost of innovation, the decentralized equilibrium achieves an efficient direction of technological development in the North. Clearly, this result hinges on the lack of distortions that are asymmetric across sectors. A recent literature has emphasized that resource misallocation may be an important source of productivity differences across countries (see, e.g., Parente, Rogerson and Wright (2000), and Hsieh and Klenow (2007)). According to this view, even though high-productivity technologies are adopted by some firms in developing countries, these firms must compete on unequal grounds with local firms using less productive technologies. This can be due to political linkages or other distortions. For instance, Song, Storesletten and Zilibotti (2008) construct a model focusing on China where discrimination in the financial sector allows large state-owned firms to survive and compete for the allocation of labor and capital with technologically more advanced private firms.

This literature has generally ignored another channel through which discriminatory policies affects aggregate productivity, i.e., its influence on the direction of technical progress. To study this effect, recall that, in each sector, the profit share is $1 / \sigma$. Assume now that $\sigma$ varies across sectors. Then, equation (12) becomes:

$$
\frac{\pi_{H}}{\pi_{L}}=\frac{\sigma_{L} P_{H} Z H}{\sigma_{H} P_{L} L}=\frac{\sigma_{L}}{\sigma_{H}}\left(\frac{A_{H}}{A_{L}}\right)^{-\frac{1}{\epsilon}}\left(\frac{Z H}{L}\right)^{1-\frac{1}{\epsilon}}
$$

Consider the North, first. Imposing the arbitrage condition that innovation be equally profitable in both sectors, $\frac{\pi_{L}}{r}=\frac{\pi_{H}}{r}=\mu$ and using (28), we can solve for the equilibrium technology:

$$
\frac{A_{H}^{N}}{A_{L}^{N}}=\left(\frac{\sigma_{L}^{N}}{\sigma_{H}^{N}}\right)^{\epsilon}\left(\frac{Z H^{N}}{L^{N}}\right)^{\epsilon-1} .
$$

We have already seen that efficient technologies, equating the marginal product of innovation across sectors, require $\frac{A_{H}^{N}}{A_{L}^{N}}=\left(\frac{Z H^{N}}{L^{N}}\right)^{\epsilon-1}$. Comparing this with (29) shows that as long as $\sigma_{L} \neq \sigma_{H}$, the efficiency condition is not satisfied and this implies a low aggregate productivity. The reason is that less competitive sectors, where rents are more protected, attract too much innovation relative to the social optimum.

In the South the efficiency condition for the direction of technology adoption is different from that in the North, as the marginal cost of technology adoption is endogenous and differs across the two sectors. In particular, using (18), the marginal costs of technology adoption are:

$$
\frac{\partial\left(c_{H} A_{H}^{S}\right)}{\partial A_{H}^{S}}=c_{H}(1+\xi) \quad \text { and } \quad \frac{\partial\left(c_{L} A_{L}^{S}\right)}{\partial A_{L}^{S}}=c_{L}(1+\xi) .
$$

Efficiency then requires $\left(\partial Y^{S} / \partial A_{H}^{S}\right) /\left(\partial Y^{S} / \partial A_{L}^{S}\right)=c_{H} / c_{L}$. Using (30) and (18), it is easy to show that the "efficient" $A_{H}^{S} / A_{L}^{S}$ coincides with (20), proving that the laissezfaire equilibrium achieves an efficient direction of technology adoption. Thus, as in the case of the North, any asymmetric markup policy leading to a deviation from (20) 
would introduce distortions. ${ }^{13}$ However, equations (30) also make clear that the social marginal costs of adoption are higher than the private costs, $c_{L}$ and $c_{H}$. The reason is that a firm adopting a new technology increases the cost of future adoption. This negative externality is ignored by decentralized firms and leads to an inefficient level of investment in technology adoption.

\section{Globalization, Technology and the Wealth of Nations}

The forces of globalization have always been seen as major determinants of the wealth of nations and of the world income distribution. Ever since David Ricardo, traditional trade theory has focused on understanding the sources of the gains from trade and their distribution, for a given technology. However, to the extent to which technology is the prominent factor in determining cross-country income disparities, the focus of the literature has shifted to the role of trade as a vehicle of technology transfer. Moreover, trade and globalization can have first-order effects the direction of technological change which can have significant effects on productivity differences. This section is devoted to reviewing some of the key mechanisms whereby globalization can alter cross-country income disparities through its impact on the direction of technological change. ${ }^{14}$

We consider two aspects of globalization: trade in goods and international labor mobility (migration). To study the former, we start by relaxing the assumption that final goods are not traded in the benchmark two-factor model of endogenous technical change. We then use the model to illustrate the effects of both North-South and NorthNorth trade on technology and relative income. A key finding of this exercise is to show that, as argued by Acemoglu and Zilibotti (2001) and Epifani and Gancia (2008a), globalization can lead to skill-biased technical change that benefits disproportionately skill-abundant countries. Next, we study how trade, specialization and migration affect the world income distribution in a single factor version of the model. We will see that, once technology is endogenized, trade and migration can have both equalizing and unequalizing effects. In particular, as emphasized by Acemoglu and Ventura (2002), trade can promote technological convergence across countries through changes in relative prices (the terms of trade). International labor mobility, instead, can either amplify or dampen income and technology differences, depending on the value of the elasticity of substitution between goods.

\subsection{North-South trade And Skill-Biased technical Change}

We start by allowing for trade in final goods, $Y_{L}$ and $Y_{H}$, in the North-South model of section 2. This exercise, first discussed in Acemoglu and Zilibotti (2001), shows that trade leads to skill-biased technical change, which in turn can cause divergence in output per worker across countries. The intuition for this result is that trade with skill-scarce countries increases the price of skill-intensive goods and this accelerates the introduction

\footnotetext{
${ }^{13} \mathrm{~A}$ more detailed analysis of asymmetries in market power as a source of inefficiency can be found in Epifani and Gancia (2008b).

${ }^{14}$ For a more extensive treatment of the links between trade, innovation and growth see Grossman and Helpman (1991) and Ventura (2005).
} 
of skill-complement innovations. As a consequence, the skill premium increases. Given that the North is skill-abundant, it benefits relatively more from such a change in factor prices.

To see this, suppose that a skill-abundant North and a skill-scarce South are integrated into a single market for $Y_{L}$ and $Y_{H}$, that we call the World. In this scenario, the relative price of goods (10) is determined by world demand and supply:

$$
\frac{P_{H}}{P_{L}}=\left[\frac{A_{L} L^{W}}{A_{H} Z H^{W}}\right]^{\frac{1}{\epsilon}},
$$

where $A_{H}$ and $A_{L}$ are assumed to be identical everywhere (i.e., we consider the case of no barriers to technology adoption in Southern countries, $\xi \rightarrow \infty)$, while $H^{W}$ and $L^{W}$ are the world endowments of skilled and unskilled workers, respectively. Suppose now that $L^{W}$ increases, because unskilled-labor abundant countries like China and India join the world trading system. Not surprisingly, equation (31) shows that the immediate effect, for a given technology, is a rise in the relative price of the skill-intensive good. But what happens once technology is allowed to adjust?

Recall from (12) that the profitability of a skill-complement innovation depends both on the size of its market, which is proportional to the skill endowment of the North, and the price of the skill-intensive good. Given our assumption that IPRs are not protected in the South, the increase in $L^{W}$ due to globalization does not affect the market for innovations, because inventors continue to sell their blueprint in the North only. Hence, the increase in the relative price of skill-intensive goods unambiguously increases the relative profitability of skill-complement innovations:

$$
\frac{\pi_{H}}{\pi_{L}}=\frac{P_{H} Z H^{N}}{P_{L} L^{S}}=\frac{Z H^{N}}{L^{N}}\left[\frac{A_{L} L^{W}}{A_{H} Z H^{W}}\right]^{1 / \epsilon}
$$

This change in the relative incentives to innovate leads to a transition with skill-biased technical change along which $A_{H} / A_{L}$ grows, until a new balanced growth path is reached. In the new long-run equilibrium, innovations must be equally profitable in both sectors $\left(\pi_{H}=\pi_{L}\right)$. Imposing this condition, we obtain:

$$
\frac{A_{H}}{A_{L}}=\left(\frac{Z H^{N}}{L^{N}}\right)^{\epsilon}\left(\frac{L^{W}}{Z H^{W}}\right),
$$

which shows that an increase in $L^{W}$ makes technology more skill-biased.

The effect on the skill premium can be found from (11):

$$
\frac{w_{H}}{w_{L}}=\frac{P_{H} Z A_{H}}{P_{L} A_{L}}=\left(\frac{Z H^{N}}{L^{N}}\right)^{\epsilon-1}\left(\frac{L^{W}}{H^{W}}\right),
$$

where we have used (31) and (33). Intuitively, in the new balanced growth equilibrium, skilled workers earn a higher wage, not just because they are perceived as scarcer, but also because technologies are more skill-biased. ${ }^{15}$

\footnotetext{
${ }^{15}$ Comparing (34) to (11), it is immediate to verify that the endogenous reaction of technology amplifies the effect of North-South trade on the skill premium. This point is made in Acemoglu (2003), where the implications for skil premia across countries are studied extensively.
} 
What are the implications of this technological adjustment for North-South income differences? Given that trade creates a single market for goods, it equalizes both commodity and factor prices across countries (note that full specialization is ruled out by the assumption that each sector employes a specific factor.). Thus, the relative income (or productivity) per effective unit of labor of a Northern economy with endowments $L^{N}$ and $H^{N}$ and a Southern country with endowments $L^{S}$ and $H^{S}$ can be expressed as:

$$
\frac{y^{N}}{y^{S}}=\left(\frac{Z H^{S}+L^{S}}{Z H^{N}+L^{N}}\right)\left(\frac{L^{N}+\omega H^{N}}{L^{S}+\omega H^{S}}\right),
$$

where $\omega \equiv w_{H} / w_{S}$ is the skill-premium. A simple derivation shows that a higher skillpremium increases $y^{N} / y^{S}$ as long as the North is skill abundant:

$$
\frac{\partial\left(y^{N} / y^{S}\right)}{\partial \omega}>0 \text { iff } \frac{H^{N}}{L^{N}}>\frac{H^{S}}{L^{S}} .
$$

Intuitively, a country benefits relatively more from an increase in the reward of its abundant factor. We therefore conclude that skill-biased technical change induced by the increase in $L^{W}$ (globalization) amplifies the income gap between Northern and Southern economies.

\subsection{Trade, MARKet SIZE AND INEQUALITY}

We now show that even trade integration between similar countries can have analogous effects. As argued in Epifani and Gancia (2008a), trade can raise the skill premium, and hence income differences between skill-abundant and skill-scarce economies, because skill-intensive activities are more complex and benefit more from the diversification opportunities offered by larger markets. ${ }^{16}$ The point is made more easily in a static version of the model in section $2 .{ }^{17}$

First, we generalize the sectorial production functions to allow for asymmetries in the elasticity of substitution across inputs:

$$
Y_{L}=\left[\int_{0}^{A_{L}} y_{L}(i)^{\frac{\sigma(L)-1}{\sigma(L)}} d i\right]^{\frac{\sigma(L)}{\sigma(L)-1}} \text { and } Y_{H}=\left[\int_{0}^{A_{H}} y_{H}(i)^{\frac{\sigma(H)-1}{\sigma(H)}} d i\right]^{\frac{\sigma(H)}{\sigma(H)-1}}
$$

We make the crucial assumption that $\sigma(L)>\sigma(H)$, meaning that the benefit from having a wider array of intermediate inputs is stronger in the skill-intensive sector. This assumption appears quite reasonable, as skill-intensive goods are typically more complex and highly differentiated (see Epifani and Gancia 2006 and 2008a).

Second, given that we are interested in North-North trade, we assume that IPRs are fully enforced everywhere and we allow for trade in the intermediates, $y_{L}(i)$ and

\footnotetext{
${ }^{16}$ Matsuyama (2007) argues instead that the act of exporting requires more skilled labor and obtains the similar result that trade intgration is inherently skill-biased.

${ }^{17}$ The reason why we use a static approach is that the model in this section would feature unbalanced growth, with one sector disappearing asymptotically. In the interest of simplicity, the static version allows us to abstract from such a complication. For the interested reader, a similar model of unbalanced growth is build in Acemoglu and Guerrieri (2007).
} 
$y_{H}(i)$. As in the previous sections, each intermediate input is produced by a monopolist and the pricing rule (7) still applies. ${ }^{18}$ Given that the model is static, we now solve for the state of technology, $A_{L}$ and $A_{H}$, by introducing a fixed cost of $\mu$ units of labor that each firm must pay. We can still think of it as the innovation costs required to design a new variety. Free entry implies that the number of varieties in each sector will increase until the operating profits made by each firm is exactly equal to the fixed cost, $p_{z} y_{z} / \sigma(z)=\mu w_{z}$, for $z \in\{L, H\}$. Together with the pricing formula (7), this condition pins down uniquely the scale of production of each firm, $y_{L}=\mu[\sigma(L)-1]$ and $y_{H}=\mu Z[\sigma(H)-1]$. Imposing labor market clearing for the world economy and using $y_{z}$ yields the number of firms per sector: ${ }^{19}$

$$
A_{H}=\frac{H^{W}}{\mu \sigma(H)} \quad \text { and } \quad A_{L}=\frac{L^{W}}{\mu \sigma(L)}
$$

Notice that, because firm size is constant, the number of varieties in each sector is proportional to the world endowment of the relevant factor.

To solve for the skill-premium, we observe that the wage bill is now equal to the revenue of a sector. ${ }^{20}$ Thus:

$$
\frac{w_{H} H^{W}}{w_{L} L^{W}}=\frac{P_{H} Y_{H}}{P_{L} Y_{L}}=\left(\frac{Y_{H}}{Y_{L}}\right)^{\frac{\epsilon-1}{\epsilon}},
$$

where we have used (4). Using $y_{H}, y_{L}$ and (36) to solve for $Y_{H}$ and $Y_{L}$ and rearranging (37) yields:

$$
\frac{w_{H}}{w_{L}}=\omega\left(H^{W}, L^{W}\right)=\kappa^{\frac{\epsilon-1}{\epsilon}}\left(L^{W}\right)^{\frac{\sigma(L)-\epsilon}{\epsilon[\sigma(L)-1]}}\left(H^{W}\right)^{-\frac{\sigma(H)-\epsilon}{\epsilon[\sigma(H)-1]}}
$$

where $\kappa$ is an unimportant constant.

We are now in the position to study the effects of trade between similar countries. In particular, suppose that globalization brings about an enlargement of the world economy that leaves $H^{W} / L^{W}$ unchanged (yet, individual countries $i$ may differ in $H^{i} / L^{i}$ ). This will be the case if two sets of countries with similar aggregate endowments, say North America and Europe, integrate their markets. To see what happens to the skill premium, notice that this experiment is isomorphic to multiplying the endowments of both $H^{W}$ and $L^{W}$ by a common factor $\lambda>1$. The elasticity of the skill premium to such a change in scale is easily computed as:

$$
\frac{\partial \omega(\lambda H, \lambda L)}{\partial \lambda} \frac{\lambda}{\omega}=\frac{(\epsilon-1)[\sigma(L)-\sigma(H)]}{\epsilon[\sigma(L)-1][\sigma(H)-1]}>0,
$$

where the positive sign follows from the assumptions $\epsilon>1$ and $\sigma(L)>\sigma(H)$. Thus, an increase in market size raises the skill premium. The intuition for this result is simple. Trade allows to sustain a wider range of intermediate inputs, thereby increasing

\footnotetext{
${ }^{18}$ Note that, also in this model, trade equalizes factor prices, so that wages are identical in all the trading countries.

${ }^{19}$ The labor marker clearing conditions are $A_{H}\left(y_{H} / Z+\mu\right)=H^{W}$ and $A_{L}\left(y_{L}+\mu\right)=L^{W}$.

${ }^{20}$ Recall that profits are used to cover the fixed costs, which are now in units of labor.
} 
productivity. In relative terms, however, output grows more in the skill-intensive sector, where input variety is more valuable $(\sigma(L)>\sigma(H))$. With an elasticity of substitution in consumption greater than one $(\epsilon>1)$, the higher relative productivity in the skillintensive sector increases its share of total expenditure and therefore also the relative wage of skilled workers.

The implications for cross-country income disparities depend crucially on which countries we consider. If we compare newly integrated countries that differ in size, globalization has an equalizing effect. The reason is that, being part of the same world market, small countries now enjoy the same scale economies as large countries. However, if we consider countries differing in skill-abundance that were already integrated before the market enlargement (e.g., inequality between European countries), the globalization shock has an unequalizing effect. This follows from the fact that the market size expansion increases the skill premium and this is more beneficial for skill-abundant countries.

\subsection{Specialization, Migration and Technology Differences}

The models discussed so far share the property that trade equalizes factor prices. Yet, even a cursory look at international data suggests that factor rewards may be far from being equalized. It is thus important to study the impact of trade on technology when we deviate from Factor Price Equalization (FPE). This is done in this section, where we analyze a one-factor version of the model in which we break FPE by assuming that each country produces a single differentiated good. We will show that, when countries are specialized, trade may prevent income differences from exploding, even in the absence of technological spillovers. Interestingly, the lack of factor price equalization has the additional implication that workers have incentives to move towards high-wage countries. By exploring this possibility, we also briefly discuss how migration may shape technology and the wealth of nations. Perhaps surprisingly, we will see that migration can either be an equalizing or unequalizing force.

Assume that there is only one type of labor $(L)$ and that the world economy is populated by two countries only, North and South, producing differentiated goods:

$$
Y=\left[Y_{N}^{\frac{\epsilon-1}{\epsilon}}+Y_{S}^{\frac{\epsilon-1}{\epsilon}}\right]^{\frac{\epsilon}{\epsilon-1}}
$$

where $Y_{N}$ is the final good produced in the North and $Y_{S}$ is the one produced in the South. ${ }^{21}$ Sectorial production functions are:

$$
Y_{S}=E_{S}\left[\int_{0}^{A_{S}} y_{S}(i)^{\frac{\sigma-1}{\sigma}} d i\right]^{\frac{\sigma}{\sigma-1}} \text { and } Y_{N}=E_{N}\left[\int_{0}^{A_{N}} y_{N}(i)^{\frac{\sigma-1}{\sigma}} d i\right]^{\frac{\sigma}{\sigma-1}}
$$

where $E_{S} \equiv\left(A_{S}\right)^{\frac{\sigma-2}{\sigma-1}}\left(E_{N} \equiv\left(A_{N}\right)^{\frac{\sigma-2}{\sigma-1}}\right)$. Notice that $A_{N}$ and $A_{S}$ now capture the state of technology in the North and South, respectively. Thus, the two countries benefit

\footnotetext{
${ }^{21}$ Equivalently, one can assume $L^{N}=0$ and $H^{S}=0$. In both cases, countries produce differentiated goods, as in the Armington model. Complete specialization can also be derived as the equilibrium outcome of more general models. For example, Bonfiglioli and Gancia (2008) obtain specialization by adding Ricardian comparative advantage in a model of endogenous technical change with a continuum of goods.
} 
from different technologies that evolve independently. The rest of the model, however, is essentially identical to the benchmark case.

Given that there is only one factor, per capita income differences are now summarized by the relative wage, $w_{N} / w_{S}$. To find it, we can use equation (11) with the appropriate change of notation:

$$
\frac{w_{N}}{w_{S}}=\frac{P_{H} Y_{H} L_{S}}{P_{S} Y_{S} L_{N}}=\left[\frac{A_{N}}{A_{S}}\right]^{1-1 / \epsilon}\left[\frac{L_{S}}{L_{N}}\right]^{1 / \epsilon},
$$

where $L_{N}$ and $L_{S}$ are the labor endowments of the North and South, respectively. It is instructive to compare this with the relative wage in autarky, where $P_{N}=P_{S}=1$ :

$$
\frac{w_{N}}{w_{S}}=\frac{A_{N}}{A_{S}},
$$

Note first that, so long as $\epsilon>1$, trade tends to reduce the effect of technological differences, $A_{N} / A_{S}$, on relative income. The intuition for this result is that terms of trade movements $\left(P_{N} / P_{S}\right)$ create productivity spillovers whereby high productivity in one country also benefits the trading partner: after trade opening, demand for the good produced by the low-income, low-productivity country increases and this leads to a favorable change in the relative price $P_{N} / P_{S}$. Second, under free trade, small countries tend to be relatively richer, because the price of their products is relatively high. This result, that is typical in trade theory, may no longer hold when technology is endogenous.

To solve for the equilibrium productivity gap, $A_{N} / A_{S}$, consider the R\&D sector. We assume that the cost of designing a new intermediate input is $\mu_{N}$ for the North and $\mu_{S}$ for the South, with $\mu_{N}<\mu_{S}$. This captures the higher R\&D potential of the North. A first important result is that trade based on specialization prevents $A_{N} / A_{S}$ from exploding. The intuition is that an increase in $A_{N} / A_{S}$ leads to a fall in the relative price of Northern products $P_{N} / P_{S}$ and this discourages further innovation in the North. In other words, for the same reason why in Section 2 the skill-bias $A_{H} / A_{L}$ settles to an equilibrium level, the productivity gap here converges to a constant value. To find it, we impose the familiar R\&D arbitrage condition, $\pi_{N} / \mu_{N}=r=\pi_{S} / \mu_{S}$. Analogously to (13), this condition yields:

$$
\frac{A_{N}}{A_{S}}=\left(\frac{\mu_{S}}{\mu_{N}}\right)^{\epsilon}\left(\frac{L_{N}}{L_{S}}\right)^{\epsilon-1}
$$

which, together with (39), implies:

$$
\frac{w_{N}}{w_{S}}=\left(\frac{\mu_{S}}{\mu_{N}}\right)^{\epsilon-1}\left(\frac{L_{N}}{L_{S}}\right)^{\epsilon-2} .
$$

With free trade, countries with a better R\&D technology (low $\mu$ ) are relatively richer, but the world income distribution is stable in the sense that both countries grow at the same rate.

On the contrary, in autarky the growth rate of each country is determined independently. Using (17) with the appropriate change of notation we get:

$$
g_{N}=\frac{L_{N}}{\mu_{N} \sigma}-\rho \quad \text { and } \quad g_{S}=\frac{L_{S}}{\mu_{S} \sigma}-\rho
$$


Thus, so long as $L_{N} / \mu_{N} \neq L_{S} / \mu_{S}$, countries in autarky are on a divergent path. This result, that trade helps to sustain a stable income distribution through changes in relative prices, was first emphasized by Acemoglu and Ventura (2002) in a model of growth through capital accumulation. Our analysis extends their finding to a model with technological change. ${ }^{22}$

A second interesting result concerns the effect of population size on income differences. While (39) shows that small countries tend to be richer because they enjoy high export prices, equation (41) suggests the effect of country size to be more complex once technology is endogenous. The new mechanism at work is that larger markets attract more innovation (see equation 40). When $\epsilon>2$, the market size effect dominates the adverse relative price effect, so that larger countries are now wealthier. This finding has important implications for the impact of migration on income differences. To see this, assume that workers move towards the country with higher wages, but that mobility is imperfect, so that some workers are always left in both nations. For example, this could be the case if workers have heterogeneous mobility costs. In this scenario, the effect of migration depends crucially on the value of $\epsilon$. If $\epsilon<2$, migration is an equalizing force: workers move to the country where they are scarce and this tends to reduce wage differentials. On the contrary, if $\epsilon>2$, the endogenous reaction of technology implies that migration increases the relative wage of the recipient country. It follows that workers move to the country where they are abundant. In this case, migration is an unequalizing force that can make a symmetric equilibrium unstable and give rise to multiple equilibria: as workers move to one country, the local wage increases and this attract further workers. Models of this type, emphasizing how globalization can generate a cumulative process of uneven development have been proposed, among others, by Matsuyama (1995 and 2004) and Krugman and Venables (1995).

\section{Conclusions}

Technology is the most important element in explaining cross country income differences. In this paper, we have illustrated how theories of directed technological change and adoption can help explain why some countries are so much more productive than others. Rather than providing an exhaustive survey, we opted for building a workhorse model that is rich enough to encompass some, albeit certainly not all, of the most credited theories of TFP differences. In particular, we have discussed three possible explanations: technological inappropriateness, barriers to technology adoption, and technological inefficiencies due to misallocations of resources within countries. We have also studied how various aspects of globalization can affect technical change and productivity differences.

Despite important advances made in the literature in recent years, several questions remain open. Among them, two issues are particularly relevant. First, our focus on technology has led us to abstract almost entirely from other sources of growth. Inte-

\footnotetext{
${ }^{22}$ The result that trade opening generates convergence depends on the absence of technology transfer in autarky. Bonfiglioli and Gancia (2008) show that, when the South can copy the technology of the North, trade can lead to divergence: as countries specialize in different sectors, R\&D become more concentrated on the goods produced by the North. Thus, trade-induced specialization can shift the direction of technical progress in favor of rich economies.
} 
grating physical and human capital accumulation into models of endogenous technical progress and studying their interaction in explaining productivity differences seems a fruitful avenue for future research. Second, one of the most important remaining challenges is to quantify the empirical merits of the complementary mechanisms illustrated in this paper. We hope that the unified theoretical framework that we have proposed can prove useful to make progress in these crucial tasks.

\section{Literature Cited}

Acemoglu D. 1998. Why do new technologies complement skills? Directed technical change and wage inequality. Quart. J. Econ. 113(4):1055-90.

Acemoglu D. 2002. Directed technical change. Rev. Econ. Stud. 69(4): 781-809.

Acemoglu D. 2003. Patterns of skill premia. Rev. Econ. Stud. 70(2): 199-230.

Acemoglu D, Aghion P, Zilibotti F. 2006. Distance to frontier, selection and economic growth. Eur. Econ. Rev. 4(1):37-74.

Acemoglu D, Guerrieri V. 2008. Capital deepening and non-balanced economic growth. J. Polit. Economy 116(3):467-98.

Acemoglu D, Gancia G, Zilibotti F. 2008. Innovation, Standardization and Technology Life Cycle. Unpublished, Univ. Zurich.

Acemoglu D, Ventura J. 2002. The world income distribution. Quart. J. Econ. 117(2): 659-94.

Acemoglu, D, Zilibotti F. 2001. Productivity differences. Quart. J. Econ. 116(2): 563-606.

Aghion P, Bloom N, Blundell R, Griffith R, Howitt P. 2005. Competition and innovation: an inverted-U relationship. Quart. J. Econ. 120(2): 701-28.

Aghion P, Howitt P. 1998. On the macroeconomic effect of major technological change. In General Purpose Technologies and Economic Growth, ed. E Helpman, pp. 12144. Cambridge: MIT Press.

Banerjee A, Duflo E. 2005. Growth theory through the lens of development economics. In Handbook of Economic Growth. Vol. 1A, ed. P Aghion, S Durlauf, pp. 473-552. Amsterdam: North Holland.

Barro RJ, Lee JW. 2000. International data on educational attainment. Work. Pap. 7911, NBER.

Barro RJ, Sala-i-Martin X. 1997. Technological diffusion, convergence, and growth. J. Econ. Growth 2(1): 1-26. 
Berman E, Bound J, Machin S. 1998. Implications of skill-biased technological change: international evidence. Quart. J. Econ. 113(4):1245-79.

Berman E, Machin S. 2000. Skill-biased technology transfer around the world. Oxford Rev. Econ. Pol. 16(3), 12-22.

Bernanke BS, Gürkaynak RS. 2001. Is growth exogenous? Taking Mankiw, Romer, and Weil seriously. Work. Pap. 8365, NBER.

Boldrin M, Levine DK. 2008. Against Intellectual Monopoly. Cambridge: Cambridge University Press.

Bonfiglioli A, Gancia G. 2008. North-south trade and directed technical change. J. Int. Econ. forthcoming.

Caselli F. 2005. Accounting for income differences across countries. In Handbook of Economic Growth. Vol. 1A, ed. P Aghion, S Durlauf, pp. 679-741. Amsterdam: North Holland.

Caselli F, Feyrer J. 2007. The marginal product of capital. Quart. J. Econ. 122(2), 535-68.

Caselli F, Wilson DJ. 2004. Importing technology. J. Monet. Econ. 51(1):1-32.

Coe D, Helpman H, Hoffmaister A. 2008. International R\&D spillovers and institutions. Work. Pap. 14069, NBER.

Dalgaard C-J, Kreiner C. 2001. Is declining productivity inevitable? J. Econ. Growth 6(3):187-203.

Diwan I, Rodrik D. 1991. Patents, appropriate technology, and north-south trade," J. Int. Econ. 30(1-2):27-48.

Epifani P, Gancia G. 2006. Increasing returns, imperfect competition and factor prices. Rev. Econ. Statist. 88(4):583-98.

Epifani P, Gancia G. 2008a. The skill bias of world trade. Econ. J. 118(530):927-60.

Epifani P, Gancia G. 2008b. Trade, markup heterogeneity and misallocations. Unpublished, CREI.

Gancia G, Zilibotti F. 2005. Horizontal innovation in the theory of growth and development. In Handbook of Economic Growth. Vol. 1A, ed. P Aghion, S Durlauf, pp. 111-70. Amsterdam: North Holland.

Gourinchas P-O, Jeanne O. 2006. The elusive gains from international financial integration. Rev. Econ. Stud. 73(3):715-41.

Grossman G, Helpman E. 1991. Innovation and Growth in the World Economy. Cambridge: MIT Press. 
Hall R, Jones CI. 1999. Why do some countries produce so much more output per worker than others? Quart. J. Econ. 114(1):83-116.

Helpman E, Trajtenberg M. 1998. A time to sow and a time to reap: growth based on general purpose technologies. In General Purpose Technologies and Economic Growth, ed. E Helpman, pp. 55-84. Cambridge: MIT Press.

Hsieh C-T, Klenow PJ. 2007. Misallocation and manufacturing TFP in China and India. Work. Pap. 13290, NBER.

Katz L, Murphy K. 1992. Changes in relative wages, 1963-1987: supply and demand factors. Quart. J. Econ. 107(1):35-78.

Krugman P, Venables A. 1995. Globalization and the inequality of nations. Quart. J. Econ. 110(4):857-80.

Matsuyama K. 1995. Complementarities and cumulative processes in models of monopolistic competition. J. Econ. Lit. 33(2): 701-29.

Matsuyama K. 2004. Financial market globalization, symmetry-breaking, and endogenous inequality of nations. Econometrica, 72(3):853-84.

Matsuyama K. 2007. Beyond icebergs: towards a theory of biased globalization. Rev. Econ. Stud. 74(1):237-53.

Nelson RR, Phelps ES. 1966. Investment in humans, technological diffusion, and economic growth. Amer. Econ. Rev. 56(2):69-75.

Parente SL, Prescott EC. 1994. Barriers to technology adoption and development. J. Polit. Economy 102(2):298-321.

Parente SL, Prescott EC. 2000. Barriers to Riches. Cambridge: MIT Press.

Parente SL, Rogerson R, Wright R. 2000. Homework in development economics: household production and the wealth of nations. J. Polit. Economy 108(4):680-87.

Restuccia D, Rogerson R. 2007. Policy distortions and aggregate productivity with heterogeneous plants. Work. Pap. 13018, NBER.

Romer P. 1990. Endogenous technological change. J. Polit. Economy 98(5):71-102.

Song Z, Storesletten K, Zilibotti F. 2008. Growing like China. Work. Pap., Univ. Zurich.

Ventura J. 2005. A global view of economic growth. In Handbook of Economic Growth. Vol. 1B, ed. P Aghion, S Durlauf, pp. 1419-97. Amsterdam: North Holland.

Zilibotti F. 2008. Economic growth through the development process. CESifo Econ. Stud. 54(3):325-58. 

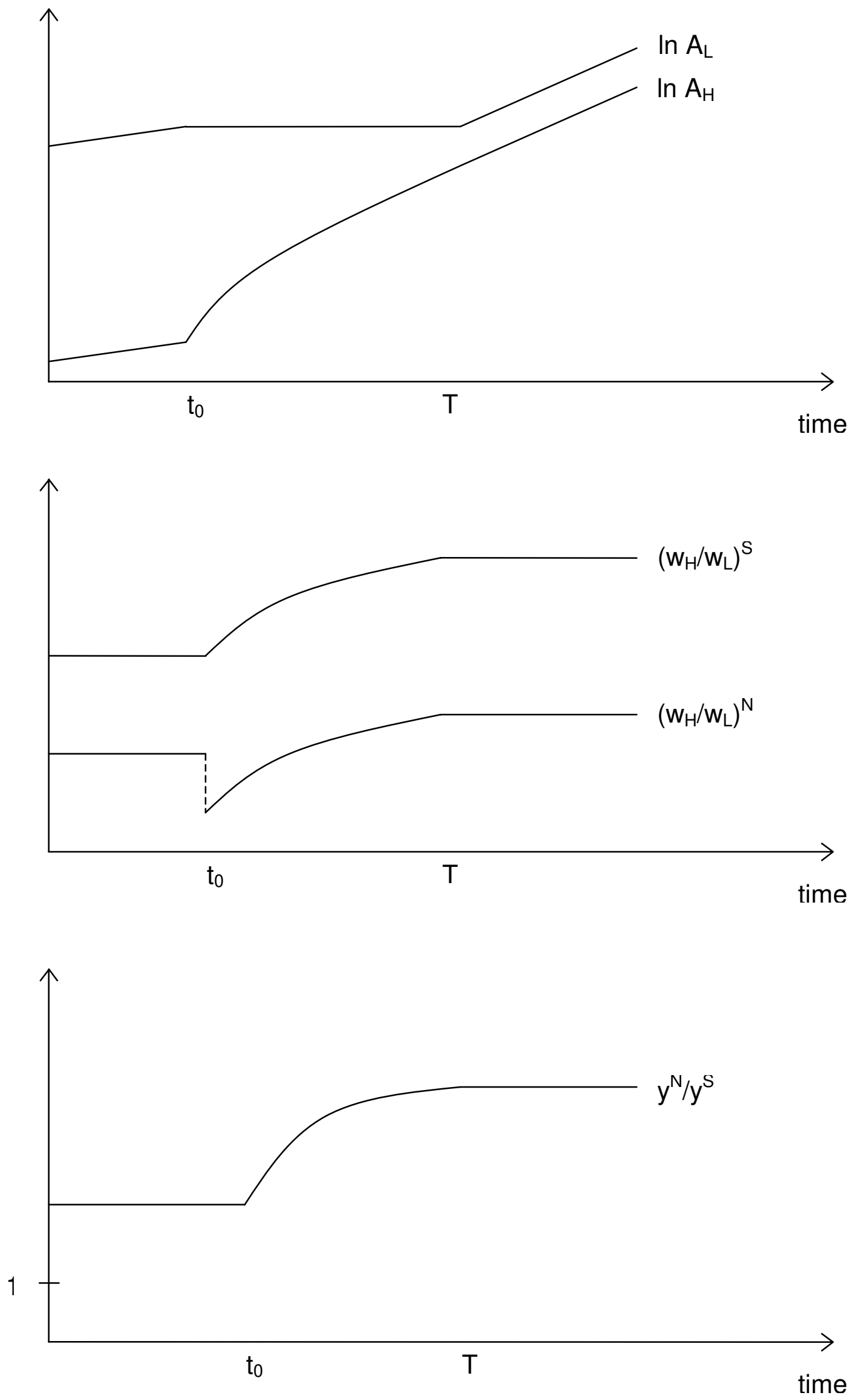

Figure 1: Skill-biased technical change after an increase in $\mathrm{H}^{\mathrm{N}}$ 